einstein

Official Publication of the Instituto Israelita

de Ensino e Pesquisa Albert Einstein

ISSN: 1679-4508 | e-ISSN: 2317-6385

\title{
Needs of family members of patients in a coronary care unit
}

Alue Constantino Coelho', Camila Takáo Lopes', Juliana de Lima Lopes', Vinicius Batista Santos', Alba Lucia Bottura Leite de Barros ${ }^{1}$

1 Escola Paulista de Enfermagem, Universidade Federal de São Paulo, São Paulo, SP, Brazil.

DOI: 10.31744/einstein_journal/2022A06258

\section{ABSTRACT}

Objective: To identify the need of family members of patients hospitalized in a coronary intensive care unit and their degree of satisfaction with the care provided. Methods: An observational and cross-sectional study including family members of patients hospitalized in the coronary intensive care unit for acute coronary syndrome in Killip I or II. After the second visit of the same family member to the patient in the unit, a 43-item inventory of needs and stressors of family members was applied. Family members assessed each need for its importance and satisfaction using a four-point Likert scale. The scores in each dimension of importance and satisfaction were compared using the Wilcoxon test, considering a value of $p<0.05$ as significant. Results: One hundred family members were interviewed. The most important needs were related to assurance and information. Family members had satisfaction scores corresponding to be very satisfied or totally satisfied, but with lower scores when compared to the needs scores $(p<0.01)$. Conclusion: The most important needs of family members of patients hospitalized in the coronary intensive care unit were related to assurance and information. Multiprofessional interventions involving better communication of patient information to family members should be incorporated into the coronary intensive care unit.

Keywords: Family; Inpatients; Patient-centered care; Critical care; Nursing; Humanization of assistance; Acute coronary syndrome; Intensive care units

How to cite this article:

Coelho AC, Lopes CT, Lopes JL, Santos VB, Barros AL. Needs of family members of patients in a coronary care unit. einstein (São Paulo). 2022;20:eA06258.

Corresponding author:

Alba Lucia Bottura Leite de Barros

Rua Napoleão de Barros, 754, $2^{\text {nd }}$ floor, room 2.016 - Vila Clementino

Zip code: 04024-002 - São Paulo, SP, Brazil

Phone: (55 11) 5576-4430 - branch line 1649

E-mail: barros.alba@unifesp.br

Received on:

Oct 20, 2020

\section{Accepted on:}

Mar 15, 2021

\section{Confict of interest:}

none.

Copyright 2022

(c) BY

This content is licensed

under a Creative Commons

Attribution 4.0 International License.

\section{INTRODUCTION}

Family members of patients hospitalized in intensive care units (ICU) frequently have negative emotional reactions, such as stress, anxiety, depression, fear, guilt, anger, insecurity, anguish, acute stress disorder, and post-traumatic stress disorder. In addition to these issues, impaired sleep quality leads to high levels of physical and emotional exhaustion. ${ }^{(1-3)}$

Some factors contributing to these reactions include the unfamiliar environment, the complex level of technology used in intensive care environments, the clinical severity of the patients, the lack of clarification of doubts, the impossibility to stay full time with their loved one, and the communication failure. ${ }^{(1,2)}$

Studies indicate that the main needs of family members of patients in the ICU are those related to assurance, information, and proximity. ${ }^{(4,5)}$ To reduce the occurrence of negative emotional symptoms of family members, meet their needs and increase their level of satisfaction with the care provide, a series of interventions that meet the principles of the Patient and Family Centered Care (PFCC) model may be carried out. ${ }^{(6)}$

From the PFCC perspective, care delivery must meet the wishes, needs, and preferences of patients and their families. ${ }^{(5-7)}$ In this context, identifying the 
needs of family members and assessing satisfaction with care delivery are indispensable for the implementation of PFCC principles.

In 1979, Nancy Molter carried out the first study to identify the perceived needs of family members of critically ill patients. Based on this study, a questionnaire was developed with 45 items, representing the importance attributed by family members to certain needs. ${ }^{(8)}$ In 1986, this tool was restructured and named Critical Care Family Needs Inventory (CCFNI). In 1991, a construct validation study of the CCFNI was carried out with 677 family members of patients in the ICU, in which the items were grouped in five dimensions: support, comfort, information, proximity, and assurance. ${ }^{(9)}$

Internationally, this instrument has undergone several types of validation and cross-cultural adaptation in different languages, and in the last 5 years it was translated and adapted into Spanish. ${ }^{(10)}$ In Brazil, the instrument was cross-culturally adapted and named Inventário de Necessidades e Estressores de Familiares em Terapia Intensiva (INEFTI)."(11,12)

Although the instrument has been applied in various types of ICU, there is a gap regarding the needs of family members of patients in the coronary ICU, because these patients are often not in critical condition, but they are admitted to this environment for surveillance and cardiovascular clinical stabilization. In this sense, identifying the needs of these family members and their level of satisfaction with care delivery may support the establishment of institutional routines, especially, nursing interventions aimed at relieving the discomfort and suffering of family members.

\section{OBJECTIVE}

To identify the needs of family members of patients hospitalized in a coronary intensive care unit and their degree of satisfaction with the care provided.

\section{METHODS}

\section{Design of the study}

A cross-sectional, descriptive study reported based on the Strengthening the Reporting of Observational Studies in Epidemiology (STROBE) guidelines. ${ }^{(13)}$

\section{Study setting}

Data collection was carried out in the coronary ICU of a large public university hospital in the city of São Paulo (SP). The ICU had six beds for patients with acute coronary syndrome (ACS), with an average of 40 admissions per month. Family visits to the patients occurred once a day for 2 hours, with no restrictions as to the number of visits, however, two visitors at a time were allowed. The family members waited at the door of the ICU, where there were two armchairs and a sofa with capacity for three seats. The patient's status was transmitted by the on-duty physician to the family member identified by the patient as responsible.

\section{Sample}

The sample consisted of family members over 18 years of age of patients admitted to the coronary ICU for ACS without clinical signs of acute ventricular dysfunction, able to understand and respond to the instruments and who had already visited the patient in the hospital at least once.

Family members of patients in Killip III or IV were excluded, since the greater severity of these patients could directly influence the needs of family members. In this study, the term "family member" is defined as a member of the patient's family, living in the same household as the patient, who received information about the patient during visiting hours or whom the patient identified as significant in their care.

\section{Data collection}

Data were collected from March 2016 to January 2018. At the time of the visit, family members who were visiting the patients for the second time were identified, and the objective of the study was presented. After accepting to participate in the research and signing the Informed Consent Form, the individuals were referred to a private room to answer the instruments in an interviewing.

Two instruments were applied. The first instrument referred to the sociodemographic characterization of the relatives and patients (age, gender, degree of kinship, marital status, religion, education, and family income). The second instrument was the INEFTI and aimed at assessing the importance family members attributed to a list of 43 needs, using a 4-point Likert-type scale $(1=$ not at all important; $2=$ not very important; $3=$ very important; $4=$ absolutely important). ${ }^{(11)}$

In addition to attributing importance considering a list of needs, family members attributed the degree of satisfaction with the care provided, taking into account each need, also by means of 4-point Likert-type scale $(1=$ not at all satisfied; $2=$ not very satisfied; $3=$ very satisfied; $4=$ totally satisfied). ${ }^{(11)}$ 
The list of 43 needs evaluated according to the degree of importance and satisfaction was grouped in five dimensions: support, which reflects the need of the family for resources and specialized help; information, which comprises the need of the family to understand the patient's condition; comfort, which relates to the wish of the family to be physically comfortable to reduce suffering and anguish; closeness, which refers to the need of the family to maintain their relationship with the patient; and assurance, related to the wish of the family to maintain or redefine hope about the patient's outcome. ${ }^{(11,12)}$

The INEFTI presented a reliability by Cronbach's alpha test of 0.79 in the total scale, regarding importance, and of 0.86 , regarding satisfaction. ${ }^{(14)}$

\section{Data analyses}

Data were analyzed in IBM SPSS, version 22.0. The absolute and relative frequency distributions, means and standard deviations were used to summarize the demographic characteristics of the participants. To analyze the needs of family members in relation to importance and satisfaction, the mean and standard deviation were calculated for each indicator and each dimension of the INEFTI. The frequency of items with score greater than or equal to three was calculated, considering that this score is related to higher importance and satisfaction. ${ }^{(14)}$ The Wilcoxon test was used to compare the differences between the importance and satisfaction of each dimension assessed by family members. The level of statistical significance was set at 0.05 .

\section{Ethical aspects}

The Ethics Committee of the Escola Paulista de Enfermagem of the Universidade Federal de São Paulo (UNIFESP) approved this study, \# 1.327.637, CAAE: 50468915.8.0000.5505. This is in accordance with the guidelines governing research involving human beings. Participants information were maintained confidential, anonymous, and they had possibility of leaving the study at any time.

\section{RESULTS}

A total of 460 family members were assessed for eligibility after their first visit to the patient. Among these, 360 were excluded: 100 patients were hospitalized for less than 24 hours, 98 patients were sedated or hemodynamically unstable, and 162 did not return to visit the patient 24 hours after the admission.
A final sample of 100 family members was obtained. Most family members were women, aged between 18 and 30 years, married, catholic, had a high school education and monthly income between one and three Brazilian minimum wages (Table 1).

From the INEFTI list of 43 needs, 35 (81\%) were considered important or very important, highlighting: "to know the patient's chance of improvement," to be assured that the best care possible is being give to the patient," to know specific facts concerning the patient's progress," to know why things were done for the patient," and to know how the patient is being treated medically." Of the 35 indicators rated as important or very important by family members, six were rated with dissatisfaction or low satisfaction, highlighting: "having a person who can provide information over the phone," "to have someone to help with financial problems", and "to know that other professionals can help me" (Table 2).

Table 1. Sociodemographic characterization of family members of patients hospitalized in the coronary intensive care unit

\begin{tabular}{lc}
\hline Sociodemographic variables & $\mathbf{n}(\%)$ \\
\hline Gender & \\
Women & $71(71)$ \\
Male & $29(29)$ \\
Age range, years & \\
18-30 & $28(28)$ \\
$31-40$ & $24(24)$ \\
$41-50$ & $17(17)$ \\
$51-60$ & $22(22)$ \\
$61-70$ & $7(7)$ \\
$>70$ & $2(2)$ \\
Relationship with patient & \\
Son/Daughter & $53(53)$ \\
Partner & $36(36)$ \\
Others & $5(5)$ \\
Brother & $4(4)$ \\
Boyfriend & $1(1)$ \\
Mother & $1(1)$ \\
Marital status & \\
Married & $46(46)$ \\
Single & $32(32)$ \\
Stable union & $15(15)$ \\
Divorced & $6(6)$ \\
Widow and Widowed & $1(1)$ \\
Religion & \\
Catholic & $47(47)$ \\
Evangelical & $24(24)$ \\
Spiritualist & $10(10)$ \\
Christian & $6(6)$ \\
None & $4(4)$ \\
Other & \\
\hline & \\
\hline
\end{tabular}


Table 2. Needs of family members of patients hospitalized in the coronary intensive care unit related to importance and satisfaction

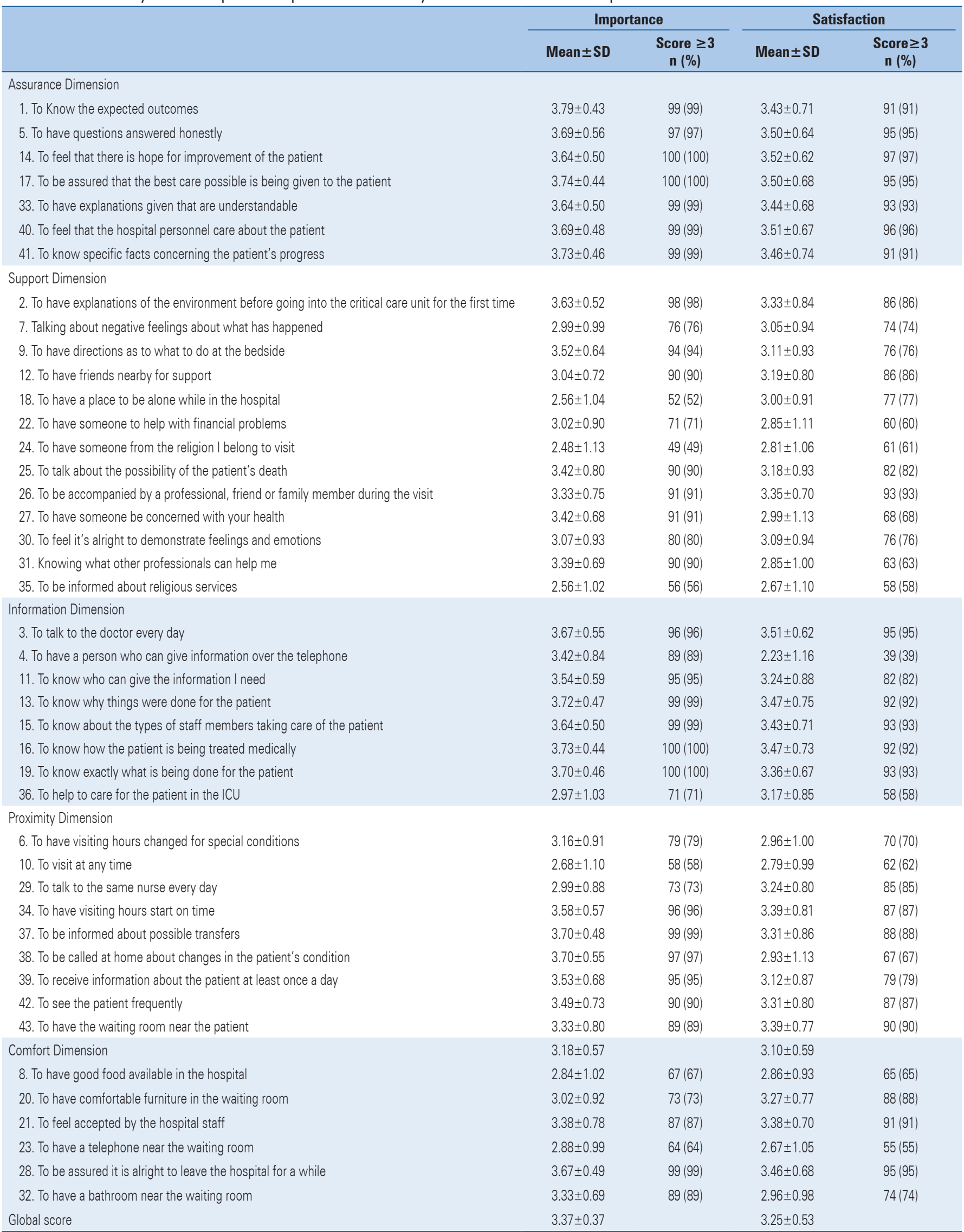

SD: standard deviation; ICU: intensive care unit. 
The dimensions considered most important were assurance, information, and proximity. The dimensions of satisfaction with the lowest scores were comfort, proximity, and information. All dimensions of INEFTI presented higher scores of importance when compared with the satisfaction scores, except for the Support Dimension and the global score, which were not significantly different (Table 3 ).

Table 3. Comparison between level of importance and level of satisfaction of family members of patients hospitalized in the coronary intensive care unit

\begin{tabular}{lccc}
\hline Dimension & $\begin{array}{c}\text { Importance } \\
\text { Mean } \pm \text { SD }\end{array}$ & $\begin{array}{c}\text { Satisfaction } \\
\text { Mean } \pm \text { SD }\end{array}$ & p value* $^{*}$ \\
\hline Assurance & $3.70 \pm 0.36$ & $3.40 \pm 0.48$ & $<0.001$ \\
Support & $3.13 \pm 0.49$ & $3.38 \pm 0.64$ & 0.669 \\
Information & $3.51 \pm 0.38$ & $3.23 \pm 0.59$ & $<0.001$ \\
Proximity & $3.35 \pm 0.47$ & $3.16 \pm 0.62$ & 0.004 \\
Comfort & $3.18 \pm 0.57$ & $3.10 \pm 0.59$ & $<0.001$ \\
Global score & $3.37 \pm 0.37$ & $3.25 \pm 0.53$ & 0.07 \\
\hline
\end{tabular}

*Wilcoxon test.

SD: standard deviation.

\section{DISCUSSION}

The needs of families of hospitalized patients are often disregarded due to the complexity of the intensive care environment by the technical and reductionist behavior of providers, and the lack of training in appropriate communication with family members. ${ }^{(15,16)}$ For this reason, one of the intensive care nurses' responsibilities is to identify the specific needs of family members and implement appropriate and essential interventions. ${ }^{(17)}$ In this study, the importance assigned to the needs of family members of patients hospitalized in a coronary ICU and the satisfaction with care were assessed and compared.

The main characteristics of PFCC in the ICU are to provide care that respects and responds to the individual preferences, needs, and values of patients and families, particularly, in an attempt to ensure that the wishes of patients and families are the guide for all clinical decisions. The key element of PFCC in the ICU is the active and direct involvement of family members and patients in decisions and self-care, ensuring physical and emotional comfort, with adequate understanding of the clinical status. ${ }^{(18)}$

This survey found that needs considered of greatest importance by family members were related to safety and information, mainly regarding the patient's treatment, with clear and precise information about patients' clinical evolution, as shown in findings of another study. This finding corroborates other studies carried out in intensive care settings but not specifically in a coronary ICU. ${ }^{(19,20)}$ Communication is an important need of family members of patients in the $\mathrm{ICU}^{(20)}$ and is part of the professional-patient-family relationship.

Studies $^{(4,21)}$ addressing identification of perceived needs of family members of critically ill patients confirm the need for honest and frequent information by families about the status of hospitalized patients, recovery, evolution and prognosis, corroborating the findings of this survey. For this reason, information must be transmitted using accessible and appropriate language, to meet and respect families' needs. ${ }^{(22)}$

Providers' attitudes, such as educating patients and relatives, increase satisfaction levels, reduce anxiety and improve the relatives' understanding, ${ }^{(6)}$ regardless of the patients' outcomes. ${ }^{(18,21,22)}$ Even in situations of unfavorable clinical progression, communication and support received by the multiprofessional team are the greatest predictors of family satisfaction. (18,21,22)

When families are allowed to play a more participatory role, a decrease in the number of phone calls occurs, without disregarding the family's need for information or compromising satisfaction with care delivery. ${ }^{(18)}$

The quality of communication depends on the characteristics and needs of each health care organization, the training of providers, the collaboration of the team, and providers' attitudes toward families. ${ }^{(21)}$ The mnemonic rule developed by the University of Washington, called VALUE, can help health care professionals communicate effectively with family members in order to reduce their stress and anxiety: to value what family members say; to acknowledge family members' emotions; to listen; to understand who the patient is as a person by asking family members questions, and to elicit questions from family members. ${ }^{(23)}$

Another aspect identified in previous studies, which corroborates the findings of the present study regarding the need for family members' communication, is that family members' participation in interdisciplinary visits improves decision-making and communication with the team. As a consequence, this improves family members' satisfaction. Family presence and participation are fundamental for implementation of humanized care in the ICU, ${ }^{(3,24)}$ however, at the setting where this survey was conducted, family members did not participate in the multiprofessional visits. This non-participation possibility may explain the lower satisfaction in the information and support dimensions compared with the scores of needs in the same domains. 
In our study, all dimensions of satisfaction evaluated had mean scores greater than or equal to 3, thereby, demonstrating that the level of satisfaction of the families with the service was adequate. The Comfort Dimension had the lowest satisfaction scores, especially about the physical structure, such as the importance of having a bathroom close to the waiting room, telephone, and the welcoming of family members. This finding was also identified in another study conducted in Brazil, ${ }^{(7)}$ in which the lowest level of satisfaction was found in the Comfort Dimension.

Measures must be taken to improve the physical structure and welcoming of family members, including noise reduction in the ICU and individual rooms, with space reserved for family members, as described in the PFCC implementation guidelines. ${ }^{(18)}$

These results are limited because they were carried out in only one center, which may limit generalization of results. In addition, this study was comprised of a convenience sample, and the levels of satisfaction with the needs that were met may have been underestimated, since the responses to the INEFTI may have been affected by social desirability. In this sense, periodic reassessments are indicated, including the assessment of the impact of improvement interventions.

\section{CONCLUSION}

The most important needs of family members of hospitalized patients in the coronary intensive care unit were related to safety and information - especially the communication established with members of the health care team. Family members reported being satisfied or very satisfied with the fulfillment of all dimensions of needs. Multiprofessional interventions involving better communication of information about patients to family members must be incorporated in the coronary intensive care unit.

\section{AUTHORS' CONTRIBUTION}

Alue Constantino Coelho, Vinicius Batista Santos and Alba Lucia Bottura Leite de Barros: participated in the conception, planning, data tabulation and statistical analysis, interpretation and writing of the work. Camila Takáo Lopes and Juliana de Lima Lopes: participated in the interpretation and critical review of the work. All authors approved the final version submitted.

\section{AUTHORS' INFORMATION}

Coelho AC: http://orcid.org/0000-0002-7783-8296

Lopes CT: http://orcid.org/0000-0002-6243-6497

Lopes JL: http://orcid.org/0000-0001-6915-6781

Santos VB: http://orcid.org/0000-0001-5130-5523

Barros AL: http://orcid.org/0000-0002-8923-5900

\section{REFERENCES}

1. Hekmatpou D, Ebrahimi-Fakhar HR. Addressing disruption in family life: exploration of the perceived needs of the families of patients hospitalized in critical care units in Iran. J Nurs Res. 2015;23(2):118-24.

2. Vasconcelos EV, Freitas KO, Silva SE, Baia RS, Tavares RS, Araújo JS. The daily life of relatives of patients admitted in icu: a study with socia representations. J Rev Fundam Care Online. 2016;8(2):4313-27.

3. Reis CC, Sena EL, Fernandes MH. Humanization care in intensive care units: integrative review. J Rev Fundam Care Online. 2016;8(2):4212-22.

4. Meneguin S, Matos TD, Miot HA, Pollo CF. Association between comfort and needs of ICU patients' family members: a cross-sectional study. J Clin Nurs. 2019;28(3-4):538-44

5. Goldfarb MJ, Bibas L, Bartlett V, Jones H, Khan N. Outcomes of patient- and family-centered care interventions in the ICU. a systematic review and metaanalysis. Crit Care Med. 2017;45(10):1751-61. Review.

6. The Joint Commission. Transitions of care: engaging patients and families. Quick Safety. 2015:18:1-3 [cited 2020 Dec 21]. Available from: https:// www.jointcommission.org/assets/1/23/0uick_Safety_Issue_18 November_20151.PDF

7. Davidson JE, Zisook S. Implementing family-centered care through facilitated sensemaking. AACN Adv Crit Care. 2017;28(2):200-9.

8. Molter NC. Needs of relatives of critically ill patients: a descriptive study. Heart Lung. 1979;8(2):332-9.

9. Leske JS. Internal psychometric properties of the Critical Care Family Needs Inventory. Heart Lung. 1991;20(3):236-44

10. Rojas Silva N, Padilla Fortunatti C, Molina Muñoz Y, Amthauer Rojas M. The needs of the relatives in the adult intensive care unit: cultural adaptation and psychometric properties of the Chilean-Spanish version of the critical care family needs inventory. Intensive Crit Care Nurs. 2017;43:123-8.

11. Castro DS. Estresse e estressores dos familiares de pacientes com traumatismo crânio - encefálico em terapia intensiva [tese]. Rio de Janeiro (RJ): Escola de Enfermagem Anna Nery, Universidade Federal do Rio de Janeiro; 1999. $144 \mathrm{p}$.

12. Morgon FH, Guirardello EB. Validation of a ratio scale for family needs at an intensive care unit. Rev Lat Am Enfermagem. 2004;12(12):198-203.

13. Von Elm E, Altman DG, Egger M, Pocock SJ, Gotzche PC, Vandenbroucke JP. The Strengthening the Reporting of Observational Studies in Epidemiology (STROBE) statement: guidelines for reporting observational studies. J Clin Epidemiol. 2008;61(4):344-9.

14. Freitas KS, Kimura M, Ferreira KA. Family members' needs at intensive care units: comparative analysis between a public and a private hospital. Rev Lat Am Enfermagem. 2007;15(1):84-92.

15. Grinberg AR, Tripodoro VA. Futilidad médica y obstinación familiar en terapia intensiva ¿Hasta cuándo seguir y cuándo parar? Medicina. 2017;77(6):491-6.

16. Pecanac K, King B. Nurse-family communication during and after family meetings in the intensive care unit. J Nurs Scholarsh. 2019;51(2):129-37.

17. Kynoch $K$, Chang A, Coyer F, McArdle A. The effectiveness of interventions to meet family needs of critically ill patients in an adult intensive care unit: a systematic review update. JBI Database Syst Rev Implement Reports. 2016;14(3):181-234. Review. 
18. Society of Critical Care Medicine (SCCM). The intensive care professionals. SCCM family-centered care guidelines supplement: work tools for guideline implementation. Last Updated 03.08.2020. Los Angeles (CA): SCCM; 2020 [cited 2020 Dec 21]. Available from: https://www.sccm.org/ getattachment/736d536f-4e97-4457-bdcc-365d69829e45/SCCM-FamilyCentered-Care-Guidelines-Supplement-W

19. Batista VC, Monteschio LV, Godoy FJ, Goes HL, Marcon SS, Matsuda LM. Needs of the relatives of patients hospitalized in an intensive therapy unit. Rev Fund Care Online. 2019;11(2):540-6.

20. Khatri Chhetri I, Thulung B. Perception of nurses on needs of family members of patient admitted to critical care units of teaching hospital, Chitwan Nepal: a cross-sectional institutional based study. Nurs Res Pract. 2018;1369164.
21. Velasco Bueno JM, Alonso-Ovies A, Heras La Calle G, Zaforteza Lallemand C; Equipo de investigación del Proyecto HUCl (Humanizando los cuidados intensivos). Main information requests of family members of patients in Intensive Care Units. Med Intensiva (Engl Ed). 2018;42(6):337-45.

22. Quenot JP, Ecarnot F, Meunier-Beillard N, Dargent A, Large A, Andreu P, et al. What are the ethical issues in relation to the role of the family in intensive care? Ann Transl Med. 2017; (Suppl 4):S40. Review.

23. Lautrette A, Darmon M, Megarbane B, Joly LM, Chevret S, Adrie C, et al. A communication strategy and brochure for relatives of patients dying in the ICU. N Engl J Med. 2007;356(5):469-78.

24. Kang J, Cho YJ, Choi S. State anxiety, uncertainty in illness, and needs of family members of critically ill patients and their experiences with family-centered multidisciplinary rounds: a mixed model study. PLoS One. 2020;15(6):e0234296. 